\title{
Conservation of the endangered medicinal plant Picrorhiza kurroa through in vitro multiple shoot regeneration
}

\author{
VARnika Chaudhary $^{1}$, Shalini Singh ${ }^{1}$, Rohit Sharma ${ }^{2}$, AJAY SingH ${ }^{3}$, Nishesh Sharma ${ }^{2 *}$ \\ ${ }^{1}$ Department of Biotechnology, Dolphin (PG) Institute of Biomedical and Natural Science, Dehradun, India \\ ${ }^{2}$ Department of Biotechnology, UCALS, Uttaranchal University, Dehradun, India \\ ${ }^{3}$ Department of Chemistry, UCALS, Uttaranchal University, Dehradun, India
}

\begin{abstract}
Picrorhiza kurroa, a well-known medicinal plant found in the vicinity of Himalayas, has become critically endangered over the years owing to its overexploitation for medicinal purposes. In this study, we cultured nodal segments onto MS (Murashige and Skoog) medium fortified with different concentrations of kinetin (Kn) and indole3-acetic acid (IAA). For enhanced multiple shooting, the regenerated shoots and callus were subcultured on a similar media combination (utilized for shoot bud initiation). Shoot bud induction was achieved in all media combinations with a maximum of $66.8 \%$ cultures exhibiting shoot bud regeneration in MS supplemented with $6 \mu \mathrm{M}$ $\mathrm{Kn}$ and $10 \mu \mathrm{M}$ IAA with the average number of $4.2 \pm 0.4$ shoots per culture; moreover, the regeneration of callus was reported. A subculture of regenerated shoots using similar media combinations (utilized for shoot bud induction) resulted in extensive induction and proliferation of multiple shoots. On an average, we obtained 18.6 \pm 0.4 shoots in an MS medium supplemented with $6 \mu \mathrm{M} \mathrm{Kn}$ and $4 \mu \mathrm{M}$ IAA. Similarly, a subculture of callus with preformed shoot buds resulted in a multiple shoot regeneration with a maximum of 20 shoots in an MS medium supplied with $4 \mu \mathrm{M} \mathrm{Kn}$ and $10 \mu \mathrm{M}$ IAA. The proliferation of callus was achieved in all media combinations and half-strength MS supplemented with IAA $(12 \mu \mathrm{M})$ was found to be the most appropriate medium for in vitro rooting. Note that, during the process of acclimatization, $\sim 62.4 \%$ plants survived. Thus, this study provides an effective method for the mass propagation of $P$. kurroa, which can further be worked out for establishing cell suspension cultures to analyze variations in the synthesis of bioactive metabolites under controlled conditions and in the presence of additives.
\end{abstract}

Key words: $P$. kurroa, micropropagation, multiple shooting, conservation

\section{Introduction}

Picrorhiza kurroa, commonly known as kutki, is a well-known medicinal plant because of its immense medicinal value. In the Ayurvedic medicine system, traditional medicinal uses of this plant, such as the treatment of respiratory and liver disorders, fever, chronic diarrhea, and dyspepsia, have been documented. Picrorhiza is an endemic species (Patil et al., 2013) to the Himalayan alpine region, including areas of India, China, Bhutan, Pakistan, Nepal, South East Tibet, and North Burma. It is generally distributed in the range of 3500 $-5000 \mathrm{~m}$ above sea level (Agarwal, 2003; Jan et al., 2009 ) and grows naturally in the wild form within rock cervices and organic soil. The major pharmaceutical properties of this plant include antimalarial, antineoplastic, antioxidant, anticancerous, antiallergic, antimicrobial, antimutagenic, and hepatoprotective activities, as well as immune modulation (Prajapati et al., 2007; Sharma and Thokchom, 2014; Rajkumar et al., 2011, Singh et al., 2011; Irshad et al. 2011; Masood et al., 2015). The roots and rhizomes of this plant are utilized for preparing several herbal drugs (Pandit et al., 2013). The immense medicinal potential of the plant is attributed to the presence of a wide range of phytocompounds that possess several biological or pharmacological activities. The major bioactive components of $P$. kurroa include picro-

\footnotetext{
* Corresponding author: Department of Biotechnology, UCALS, Uttaranchal University, Dehradun, India; e-mail: nishesh21@gmail.com
} 
sides, kutkosides, androsin, and catechol (Stuppner and Wagner, 1989; Praveena and Rao, 2013; Weings et al., 1972). Recently, $P$. kurroa has been listed as an endangered species (Pandit et al., 2013, Sharma et al., 2010). An unrestricted collection of $P$. kurroa from natural sources is the prime cause for present endangered status of the plant (Sood and Chauhan 2009; Masood et al., 2015; Srivastava and Srivastava, 2016). Furthermore, $P$. kurroa requires specific environmental conditions that restrict the cultivation of the plant to a specific region, making conservation of this plant species very challenging. Owing to the medicinal potential and the current endangered status of $P$. kurroa, there is a requirement for developing cultivation strategies for its mass propagation and conservation. In this study, we achieved multiple shoot regeneration from an in vitro culture of nodal segments of $P$. kurroa. We conducted this study with an aim to develop a protocol that would be rapid, effective, and easily reproducible for the mass propagation of $P$. kurroa.

\section{Material and methods}

\section{Explants source}

We procured mature plants of $P$. kurroa from the Department of Biotechnology and Bioinformatics, Jaypee University of Information Technology, Waknaghat, Solan, India which were then maintained in the Department of Biotechnology, Uttaranchal College of Applied and Lifesciences (UCALS), Uttaranchal University, Dehradun, India. Note that the nodal segments from wellgrown plants were utilized as explants.

\section{Sterilization of explants}

For the surface sterilization of explants, we followed the protocol reported Sharma et al. (2015a) with slight modifications. Nodal segments were immersed in a beaker containing water, and then the beaker was covered with a muslin cloth and placed under running tap water for $10 \mathrm{~min}$ to completely remove any external impurities attached to the nodal segments. Then, a few drops of Tween 20 were added to the beaker containing the explants, and then the container was covered with muslin cloth and kept under running tap water for $20 \mathrm{~min}$. After removing all traces of Tween 20 , the nodes were rinsed with $70 \%$ ethyl alcohol for about 50 s, and then washed with distilled water. The explants were then transferred to the laminar air flow chamber for further sterilization and surface sterilized with $0.1 \% \mathrm{HgCl}_{2}$ for $3 \mathrm{~min}$. Then, the sterilized explants were washed 3-4 times with sterile doubly distilled water (to remove all traces of $\mathrm{HgCl}_{2}$ ), dried using a sterile tissue paper, and excised to an appropriate of $\sim 2-2.5 \mathrm{~cm}$.

\section{Establishment of in vitro cultures}

As a basal culture medium, we used the Murashige and Skoog (1962) (MS) medium. Note that surface-sterilized nodal segments were inoculated on a freshly prepared culture medium. In this study, the MS media was fortified with different concentrations of kinetin $(\mathrm{Kn})$ along with varying concentrations of either 2,4-dichlorophenoxyacetic acid $(2,4-\mathrm{D})(2-8 \mu \mathrm{M})$, naphthalene acetic acid (NAA) $(2-8 \mu \mathrm{M})$, or indole-3 acetic acid (IAA) $(2-10 \mu \mathrm{M})$. The cultures were incubated at $22 \pm 2{ }^{\circ} \mathrm{C}$ with a $16 \mathrm{~h}$ photoperiod of light $\left(15 \mu \mathrm{E} / \mathrm{m}^{2} / \mathrm{s}\right.$ irradiance). Each experimental setup comprised at least 25 cultures and each experiment was repeated thrice.

\section{Subcultures of regenerated shoots and callus}

In independent experimental setups, for shoot bud induction and regeneration from callus, in vitro regenerated shoots and calli (with preformed shoot buds) were subcultured onto the MS medium, which was supplemented with $\mathrm{Kn}(2-6 \mu \mathrm{M})$ and IAA $(4-10 \mu \mathrm{M})$.

\section{In vitro rooting of regenerated shoots}

To induce rooting among in vitro regenerated shoots a half strength medium fortified with different concentrations of IAA $(2-20 \mu \mathrm{M})$ was utilized. Then, well grown and elongated shoots, $\sim 5-6 \mathrm{~cm}$ in length, were excised and aseptically transferred to a rooting medium.

\section{Acclimatization of in vitro regenerated plants}

Note that regenerated plants with well-developed roots easily acclimatized to natural conditions. For the acclimatization process, we adopted the method reported by Sharma et al. (2015b). The plants were gently removed from culture vessels under aseptic conditions, and then the roots were carefully washed with sterile distilled water to remove the media attached to the roots. Subsequently, the plants were transferred to plastic pots filled with sterilized sand and garden soil in a $1: 1$ ratio. The pots were covered with transparent polybags and incubated under similar conditions for in vitro regenera- 
tion. The pots were irrigated with water containing $1 / 4$ strength MS nutrients as per requirement to avoid both under and overirrigation. After $\sim 10$ days, when new leaves began to emerge, small cuts were made at the edges of the polybags. The plants were then transferred to a mist chamber, followed by the respective transfer to a greenhouse. Moreover, if the plants exhibited normal growth and development in a greenhouse, they were eventually transferred to natural soil.

\section{Recording of data and statistical analysis}

The cultures were regularly monitored for morphological changes and observations were accordingly recorded. The results were expressed as a percentage of cultures exhibiting a response. Note that the textures and colors of calli along with the degree of callusing were reported on the basis of visual observations. Moreover, average and maximum numbers of shoots and roots were calculated for every media combination, and the results obtained were analyzed using Duncan's Multiple Range test to determine significance for all media combinations.

\section{Result and discussion}

\section{Multiple shoot regeneration}

The regeneration of multiple shoots is considered to be the most effective application of micropropagation techniques. It has been utilized for the conservation and mass propagation of several plant species such as $\mathrm{Wi}^{-}$ thania somnifera and Withania coagulans (Sharma and Koshy, 2017), Rotala rotundifolia (Dogan, 2017), Luffa acutangula (Umamaheswari et al., 2014), Lagerstroemia indica (Niranjan et al., 2010), Asclepias curassavica (Salla et al., 2012), Catharanthus roseus (Faheem et al., 2011), Hibiscus cannabinus (Herath et al., 2004), Syzygium aromaticum (Mathew and Hariharan, 1990), and Rauwolfia serpentine (Chaudhary et al., 2016). Micropropagation studies pertaining to the conservation of medicinal plants such as Matthiola incana (Kaviani et al., 2013), Ipomoea mauritiana (Islam and Bari, 2013), Daucus carota (Ojha et al., 2012), Arachis hypogaea (Venkatachalam and Jayabalan, 1997), Withania coagulans (Sharma et al., 2016) indicated that plant growth regulators (PGRs) combinations of Kn with either 2,4-D or NAA were significantly effective for in vitro morphogenesis. However, in this study, IAA was found to be a more appropriate auxin as compared to 2,4-D or NAA when utilized in combination with $\mathrm{Kn}$ for multiple shoot bud induction from in vitro cultured nodal segments of $P$. kurroa. Furthermore, when nodal segments of $P$. kurroa were cultured in MS supplemented with $2 \mu \mathrm{M} \mathrm{Kn}$ and $4 \mu \mathrm{M}$ IAA, $38.2 \%$ cultures exhibited shoot bud induction with an average of $1.2 \pm 0.4$ shoots per culture. Moreover, when the concentration of IAA was increased to $6 \mu \mathrm{M}$ and $10 \mu \mathrm{M}$ (with $2 \mu \mathrm{M} \mathrm{Kn}$ ), $\sim 44.2 \%$ and $58.6 \%$ cultures exhibited shoot bud induction, respectively. Note that, irrespective of the concentration of IAA, a maximum of two shoots were obtained in explants grown in MS medium fortified with $2 \mu \mathrm{M} \mathrm{Kn}$. When enhancing the concentration of $\mathrm{Kn}$ to $4 \mu \mathrm{M}, 46.2 \%$ cultures exhibited multiple shoot formation on MS fortified with $4 \mu \mathrm{M}$ Kn and $4 \mu \mathrm{M}$ IAA with an average and maximum number of shoots to be $2.1 \pm 0.8$ and 3.0, respectively. In MS media supplemented with $4 \mu \mathrm{M} \mathrm{Kn}$ and $10 \mu \mathrm{M}$ IAA, $52.6 \%$ explants developed multiple shoots. Moreover, when the concentration of Kn was further increased to $6 \mu \mathrm{M}, 66.2 \%$ explants exhibited multiple shoot induction in an MS medium supplemented with $6 \mu \mathrm{M} \mathrm{Kn}$ and $2 \mu \mathrm{M}$ IAA. Furthermore, when the concentration of IAA was increased to $10 \mu \mathrm{M}$ (while ensuring the Kn concentration constant), $66.8 \%$ explants were found to develop multiple shoots. Note that the average and maximum numbers of shoots obtained on explants grown on this medium were $4.2 \pm 0.4$ and 5.0, respectively (Table 1, Fig. 1B and 1C). Several studies have reported an important role of $\mathrm{Kn}$ for inducing direct or indirect organogenesis in a number of plant species such as Rotala rotundifolia (Dogan, 2017), Matthiola incana (Kaviani et al., 2013), Asclepias curassavica (Reddy et al., 2012), Lagerstroemia indica (Niranjan et al., 2010) and Withania somnifera (Sharma et al., 2015a). Most tissue culture studies that were conducted for mass propagation of $P$. kurroa have utilized one or more plant growth PGRs for direct or indirect organogenesis; however, Sharma et al. (2010) reported the regeneration of multiple shoots from nodal explants of $P$. kurroa on a hormone-free medium in $99.94 \%$ cultures. They also reported a somatic embryogenesis in a medium supplemented with TDZ (Thidiazuron) and IBA (Indole butyric acid); however, the embryos failed to regenerate further. Unlike the results obtained by Sharma et al. (2010), we did not achieve any regeneration in a hormone-free medium. 
Table 1. In vitro culture of nodal segment of $P$. kurroa onto MS + Kn + IAA

\begin{tabular}{c|c|c|c|c|c|c}
\hline $\begin{array}{c}\mathrm{Kn} \\
{[\mu \mathrm{M}]}\end{array}$ & $\begin{array}{c}\mathrm{IAA} \\
{[\mu \mathrm{M}]}\end{array}$ & $\begin{array}{c}\text { Percent } \\
\text { of response } \\
{[\%]}\end{array}$ & $\begin{array}{c}\text { Average shoot } \\
\text { number }\end{array}$ & $\begin{array}{c}\text { Maximum } \\
\text { number } \\
\text { of shoots }\end{array}$ & $\begin{array}{c}\text { Percent } \\
\text { of culture } \\
\text { with callus } \\
{[\%]}\end{array}$ & $\begin{array}{c}\text { Degree } \\
\text { of callusing }\end{array}$ \\
\hline 2 & 4 & 38.2 & $1.3 \pm 0.4^{\mathrm{f}}$ & 2 & 22.4 & + \\
\hline 2 & 6 & 44.2 & $1.6 \pm 0.6^{\mathrm{e}}$ & 2 & 44.6 & ++ \\
\hline 2 & 10 & 58.6 & $1.6 \pm 1.2^{\mathrm{d}}$ & 2 & 62.8 & ++ \\
\hline 4 & 4 & 46.2 & $2.1 \pm 0.8^{\text {cd }}$ & 3 & 28.2 & ++ \\
\hline 4 & 6 & 49.5 & $2.5 \pm 0.5^{\mathrm{c}}$ & 4 & 46.4 & ++ \\
\hline 4 & 10 & 52.6 & $2.4 \pm 0.2^{\mathrm{c}}$ & 3 & 64.0 & +++ \\
\hline 6 & 2 & 62.6 & $1.2 \pm 0.6^{\mathrm{f}}$ & 2 & - & - \\
\hline 6 & 4 & 64.4 & $3.6 \pm 1.2^{\mathrm{b}}$ & 5 & 48.8 & +++ \\
\hline 6 & 10 & 66.8 & $4.2 \pm 0.4^{\mathrm{a}}$ & 5 & 66.2 & +++ \\
\hline
\end{tabular}

Values are mean of seven replicates; mean values followed by same letters are not significantly different at $P \geq 0.05$ DMRT

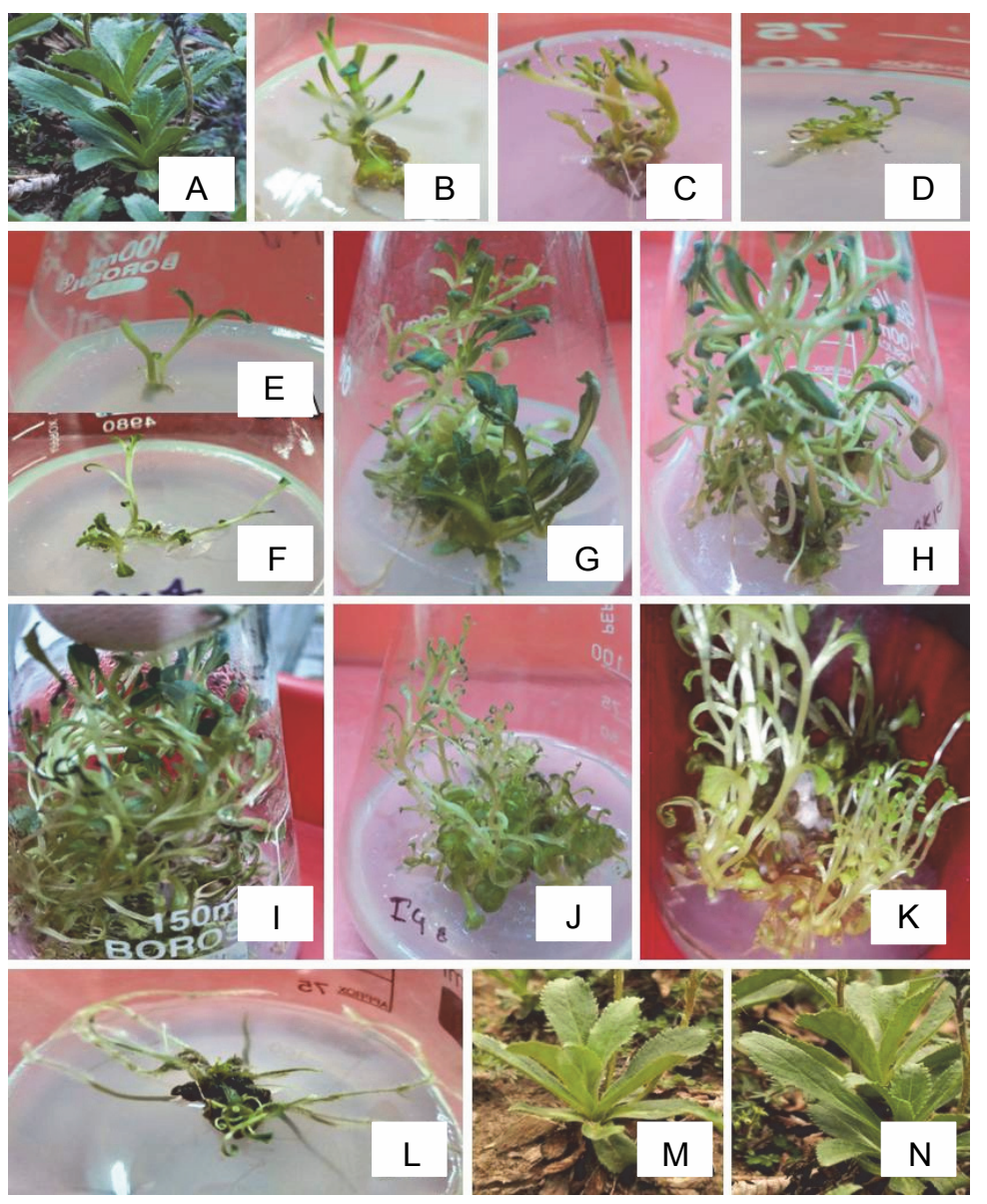

Fig. 1. A) Mother plant of $P$. kurroa; B-C) in vitro shoot regeneration and callus development onto $\mathrm{MS}+6 \mu \mathrm{M} \mathrm{Kn}+10 \mu \mathrm{M}$ IAA; D) multiple shoot induction from nodal segment onto MS $+6 \mu \mathrm{M} \mathrm{Kn}+2 \mu \mathrm{M}$ IAA; E-F) initiation of multiple shoot from subculture of in vitro regenerated shoot; $\mathrm{G}-\mathrm{H}$ ) multiple shoot regeneration from subculture of in vitro regenerated shoots onto $\mathrm{MS}+4 \mu \mathrm{M} \mathrm{Kn}+4 \mu \mathrm{M}$ IAA and $\mathrm{MS}+6 \mu \mathrm{M} \mathrm{Kn}+10 \mu \mathrm{M}$ IAA; J-K) multiple shoot regeneration from subcultured callus onto $\mathrm{MS}+4 \mu \mathrm{M} \mathrm{Kn}+8 \mu \mathrm{M}$ IAA and $\mathrm{MS}+6 \mu \mathrm{M} \mathrm{Kn}+8 \mu \mathrm{M}$ IAA respectively; L) in vitro rooting onto $1 \mathrm{MS}+12 \mu \mathrm{M}$ IAA; $\mathrm{M}-\mathrm{N}$ ) acclimatized plants, transplanted to natural soil 


\section{In vitro callusing}

In addition to the proliferation of shoot buds, a development of callus was achieved from in vitro cultures of nodal segments in all tested media combinations, except for MS supplemented with $6 \mu \mathrm{M}$ Kn and $2 \mu \mathrm{M}$ IAA (Fig. 1D) in which only the regeneration of shoots was achieved. However, depending on the concentration of PGRs in the culture medium, the percentage of explants developing a callus and the degree of callusing varied. In a medium supplemented with a low concentration of IAA (2-4 $\mu \mathrm{M})$, only a small percentage of cultures developed calli with moderate proliferation $(\geq 0.30 \mathrm{mg})$. However, with an increase in the concentration of IAA, we achieved a simultaneous increase in the percentage of cultures exhibiting callus development. Note that the Kn concentration was found to have a profound impact on the proliferation of the callus. In an MS medium supplemented with $2 \mu \mathrm{M}$ Kn and $4 \mu \mathrm{M}$ IAA, $\sim 22.4 \%$ cultures developed calli with an extremely low $(\geq 0.15 \mathrm{mg})$ degree of callusing (Table 2 ). Furthermore, $\sim 44.6 \%$ cultures exhibited callus development in an MS medium with $2 \mu \mathrm{M} \mathrm{Kn}$ and $6 \mu \mathrm{M}$ IAA with a moderate $(\geq 0.30 \mathrm{mg})$ extent of callusing. Moreover, when the concentration of IAA was further increased in an MS medium supplemented with $2 \mu \mathrm{M} \mathrm{Kn}$ and $10 \mu \mathrm{M}$ IAA, callus developed in $62.8 \%$ cultures, although the proliferation of callus was moderate $(\geq 0.30 \mathrm{mg})$. In an MS medium fortified with $4 \mu \mathrm{M} \mathrm{Kn}$ and $4 \mu \mathrm{M}$ IAA, callus developed in $28.2 \%$ cultures; moreover, the response was further enhanced to $46.5 \%$ and $64 \%$ in a culture medium with $4 \mu \mathrm{M} \mathrm{Kn}$ and $6 \mu \mathrm{M}$ IAA and MS with $4 \mu \mathrm{M} \mathrm{Kn}$ and $10 \mu \mathrm{M}$ IAA, respectively. In an MS medium supplemented with $6 \mu \mathrm{M}$ $\mathrm{Kn}$ and $4 \mu \mathrm{M}$ IAA, $48.8 \%$ of explants developed calli and the response was enhanced to $66.2 \%$ in a medium fortified with $6 \mu \mathrm{M} \mathrm{Kn}$ and $10 \mu \mathrm{M}$ IAA. For both the media combinations, an extensive $(\leq 50 \mathrm{mg})$ proliferation of callus was observed, and the calli obtained in all media combinations were fragile and green in color. Previously, in a study conducted by Sharma et al. (2010), the regeneration of callus from leaf segments of $P$. kurroa was reported in an MS medium supplemented with TDZ; MS and TDZ and IBA; MS and 2,4-D and TDZ; and MS and $\mathrm{Kn}$. In the same study, the development of the callus and a regeneration of shoots was reported from nodal segments on MS with the addition of Kn. Moreover, Helena et al. (2015) utilized leaf and nodal segments of $P$. kur- roa as explants and reported the regeneration of callus on different media combinations. In their study, an MS medium supplemented with TDZ $(0.5 \mathrm{mg} / \mathrm{l})$ and IBA $(0.3-0.5 \mathrm{mg} / \mathrm{l})$ was reported to be the optimal medium for the regeneration of calli from leaves and nodal segments. Recently, Parihar et al. (2018) reported that MS supplemented with BAP (6-Benzyl amino purine) $(0.5 \mathrm{mg} / \mathrm{l})$ and $\mathrm{Kn}(0.75 \mathrm{mg} / \mathrm{l})$ was an effective medium for the regeneration of calli from in vitro cultured leaf segments of $P$. kurroa, whereas MS fortified with BAP $(0.5 \mathrm{mg} / \mathrm{l})$ and $\mathrm{Kn}(0.75 \mathrm{mg} / \mathrm{l})$ was most suitable for the proliferation of shoots. Sood and Chauhan (2009) achieved the development of callus from in vitro cultured leaf discs, roots, and nodal segments of $P$. kurroa. In their study, an MS medium supplemented with the addition of 2,4-D ( $2 \mathrm{mg} / \mathrm{l})$ and IBA $(0.5 \mathrm{mg} / \mathrm{l})$ was reported to be the most effective medium for callus regeneration with the highest percentage of calli achieved from root segments, followed by leaves and nodes. Note that callus regeneration from the leaves of $P$. kurroa on MS medium enriched with TDZ has been previously reported by Patil et al. (2013). They also reported the regeneration of shoots using an MS medium fortified with Kn. Similarly, Lal and Ahuja (1996) reported the development of callus from leaf and nodal explants of $P$. kurroa on 2,4-D (0.5$2 \mathrm{mg} / \mathrm{l})$ supplemented with MS medium. In their study, callus proliferation was obtained on an MS supplemented with NAA (4 mg/l) and $\mathrm{Kn}(1 \mathrm{mg} / \mathrm{l})$; however, the regeneration of shoots was achieved only when the callus was subcultured on an MS supplemented with BAP.

\section{Subculture of in vitro regenerated shoots and callus}

As shown in Table 1, a low response (owing to the number of shoots regenerated with a maximum of five shoots in an MS supplemented with $2 \mu \mathrm{M} \mathrm{Kn}$ and 4 $-10 \mu \mathrm{M}$ IAA) was achieved when nodal segments were cultured on an MS medium fortified with varying concentrations of $\mathrm{Kn}$ and IAA. However, when in vitro regenerated shoots were subcultured on a freshly prepared medium containing IAA and $\mathrm{Kn}$ in different concentrations, we achieved an enhanced proliferation of regenerated shoots. In an MS supplemented with $2 \mu \mathrm{M} \mathrm{Kn}$ and $4 \mu \mathrm{M}$ IAA, we obtained an average of $14 \pm 0.2$ shoots with a maximum number of 18 shoots (Table 2). Moreover, the number of average and maximum numbers of shoots increased to $16 \pm 1.2$ and 19 , respectively, in an 
Table 2. Subculture of in vitro regenerated shoots of $P$. kurroa onto MS + Kn + IAA

\begin{tabular}{c|c|c|c|c|c|c}
\hline $\begin{array}{c}\mathrm{Kn} \\
{[\mu \mathrm{M}]}\end{array}$ & $\begin{array}{c}\text { IAA } \\
{[\mu \mathrm{M}]}\end{array}$ & $\begin{array}{c}\text { Percent of culture } \\
\text { with multiple shoot } \\
{[\%]}\end{array}$ & $\begin{array}{c}\text { Average shoot } \\
\text { number }\end{array}$ & $\begin{array}{c}\text { Maximum } \\
\text { number } \\
\text { of shoots }\end{array}$ & $\begin{array}{c}\text { Average number } \\
\text { of shoot length } \\
\text { [cm] }\end{array}$ & $\begin{array}{c}\text { Maximum } \\
\text { number } \\
\text { of shoot } \\
\text { length } \\
\text { [cm] }\end{array}$ \\
\hline 2 & 4 & 100 & $14.0 \pm 0.2^{\mathrm{e}}$ & 18 & $4.8 \pm 0.2$ & 7 \\
\hline 2 & 6 & 100 & $15.8 \pm 0.4^{\mathrm{c}}$ & 17 & $4.6 \pm 0.5$ & 6 \\
\hline 2 & 10 & 100 & $15.2 \pm 0.5^{\mathrm{cd}}$ & 20 & $4.3 \pm 0.6$ & 7 \\
\hline 4 & 4 & 100 & $16.0 \pm 1.2^{\mathrm{b}}$ & 19 & $5.1 \pm 0.4$ & 7 \\
\hline 4 & 6 & 100 & $13.4 \pm 0.4^{\mathrm{f}}$ & 17 & $5.4 \pm 0.8$ & 7 \\
\hline 4 & 10 & 100 & $15.4 \pm 0.2^{\mathrm{c}}$ & 19 & $6.0 \pm 1.2$ & 8 \\
\hline 6 & 2 & 100 & $16.2 \pm 0.6^{\mathrm{b}}$ & 25 & $6.8 \pm 0.5$ & 8.2 \\
\hline 6 & 4 & 100 & $18.6 \pm 0.4^{\mathrm{a}}$ & 24 & $6.2 \pm 0.6$ & 8.5 \\
\hline 6 & 10 & 100 & $18.4 \pm 0.4 \mathrm{a}$ & 26 & $6.8 \pm 0.4$ & 8.4 \\
\hline
\end{tabular}

Values are mean of seven replicates; mean values followed by same letters are not significantly different at $P \geq 0.05$ DMRT

Table 3. Subculture of callus with preformed shootbuds onto MS + Kn + IAA

\begin{tabular}{c|c|c|c|c}
\hline $\begin{array}{c}\mathrm{Kn} \\
{[\mu \mathrm{M}]}\end{array}$ & $\begin{array}{c}\text { IAA } \\
{[\mu \mathrm{M}]}\end{array}$ & $\begin{array}{c}\text { Average shoot } \\
\text { number }\end{array}$ & $\begin{array}{c}\text { Maximum number } \\
\text { of shoots }\end{array}$ & $\begin{array}{c}\text { Proliferation } \\
\text { of callus }\end{array}$ \\
\hline 2 & 4 & $7.8 \pm 0.2^{\mathrm{f}}$ & 11 & ++ \\
\hline 2 & 8 & $9.6 \pm 0.4^{\mathrm{d}}$ & 9 & +++ \\
\hline 2 & 10 & $8.4 \pm 0.5^{\mathrm{e}}$ & 10 & +++ \\
\hline 4 & 4 & $14.2 \pm 0.4^{\mathrm{cd}}$ & 18 & ++ \\
\hline 4 & 8 & $16.8 \pm 0.6^{\mathrm{a}}$ & 22 & +++ \\
\hline 4 & 10 & $15.0 \pm 0.6^{\mathrm{b}}$ & 20 & +++ \\
\hline 6 & 4 & $15.4 \pm 0.2^{\mathrm{b}}$ & 18 & +++ \\
\hline 6 & 8 & $16.2 \pm 1.3^{\mathrm{a}}$ & 20 & ++ \\
\hline 6 & 10 & $14.8 \pm 0.4^{\mathrm{c}}$ & 19 & ++ \\
\hline
\end{tabular}

Values are mean of seven replicates; mean values followed by same letters are not significantly different at $P \geq 0.05$ DMRT

MS medium fortified with $4 \mu \mathrm{M} \mathrm{Kn}$ and $4 \mu \mathrm{M}$ IAA. All the medium combination possessing $6 \mu \mathrm{M}$ Kn with varying concentrations of IAA exhibited extensive induction and proliferation of shoots (Table 2). Furthermore, the maximum number of 26 shoots with an average shoot number of $18.4 \pm 0.4$ was achieved in a medium with $6 \mu \mathrm{M} \mathrm{Kn}$ and $10 \mu \mathrm{M}$ IAA. Note that a subculture of callus with shoot buds on a MS medium fortified with varying concentrations of $\mathrm{Kn}$ and IAA resulted in the regeneration and proliferation of multiple shoots in all media combinations. Furthermore, we achieved an extensive proliferation of callus on media containing preferably higher IAA concentrations. As far as multiple shooting is concerned, the pre-existing shoot buds were elongated and developed into shoots with leaves; moreover, new shoots emerged from the calli, which resulted in a sufficiently good response. On an average, $7.8 \pm 0.2$ shoots per culture with a maximum of 11 shoots were obtained in an MS medium supplemented with $2 \mu \mathrm{M} \mathrm{Kn}$ and $4 \mu \mathrm{M}$ IAA. When the concentration of Kn increased to $4 \mu \mathrm{M}$, the average and maximum number of shoots on MS with $4 \mu \mathrm{M} \mathrm{Kn}$ and $4 \mu \mathrm{M}$ IAA were $14.2 \pm 0.4$ and 20 , respectively. Furthermore, a maximum of 22 shoots with an average number of $16.8 \pm 0.6$ shoots per culture were 
obtained in an MS fortified with $4 \mu \mathrm{M}$ Kn and $8 \mu \mathrm{M}$ IAA (Fig. 1J). Moreover, an equally high number of multiple shoots were obtained in an MS with the addition of $6 \mu \mathrm{M}$ $\mathrm{Kn}$ and $8 \mu \mathrm{M}$ IAA with an average number of $16.2 \pm 1.3$ and a maximum of 20 shoots (Table 3, Fig. 1K). The proliferation of callus was observed in all media combinations. Comparatively, a moderate $(\geq 0.35 \mathrm{mg})$ callus growth was obtained in a medium with $4 \mu \mathrm{M}$ IAA, whereas extensive callusing occurred at higher $(8-10 \mu \mathrm{M}) \mathrm{IAA}$ concentrations. As observed in this study, subculturing calli to achieve multiple shoot regeneration is a common approach that is successfully utilized for the mass propagation of multiple plant species. Vishwakarma et al. (2013) achieved $22.8 \pm 0.6$ shoots from the petiole callus of Viola serpens. Tejasvathi et al. (2010) reported the regeneration of a maximum number of shoots from the callus of Macrotyloma uniflorum (Lam.) Verde in an MS medium containing IBA and BAP. Similarly,multiple shooting from callus has been reported in many other plants such as Withania coagulans (Sharma and Koshy, 2017), Withania somnifera (Sharma et al., 2014), Brassica juncea (Trivedi and Dubey, 2014), and Rauwolfia serpentina (Chaudhary et al. 2015).

\section{In vitro rooting}

A half-strength MS medium fortified with IAA (2$12 \mu \mathrm{M}$ ) was used for the in vitro rooting of regenerated shoots. About $48.6 \%$ of cultures exhibited in vitro rooting in $1 / 2$ strength (concentration of major and minor nutrients reduced to half) MS medium supplemented with $4 \mu \mathrm{M}$ IAA with an average of $5.2 \pm 0.4$ roots per culture and a maximum root length of $4.8 \mathrm{~cm}$. When the concentration of IAA increased to $6 \mu \mathrm{M}$, we achieved in vitro rooting in $68.8 \%$ cultures; however, there was no noticeable increase in the average and maximum number of roots. On further increasing the concentration of IAA to $8 \mu \mathrm{M}, 84.4 \%$ cultures developed in vitro roots. Note that the roots were thick and exhibited rapid proliferation with a maximum length of $10 \mathrm{~cm}$. When the concentration of IAA was further increased to $12 \mu \mathrm{M}$, a decrease in the percentage of cultures developing in vitro roots was noted. A maximum of $54.4 \%$ cultures developed roots on $1 / 2$ strength MS medium with the addition of $12 \mu$ M IAA. Similarly, Jan et al. (2009) in their micropropagation study on $P$. kurroa achieved rooting in 92\% explants in MS supplemented with $0.4 \mathrm{mg} / 1 \mathrm{NAA}$. Howeverver, when the concentration of NAA was en- hanced to $0.8-1 \mathrm{mg} / \mathrm{l}$ the percentage of explants developing roots decreased to $30 \%$ and $20 \%$, respectively. Helena et al. (2015) reported a similar decrease in the regeneration of roots in $P$. kurroa when the concentration of the respective hormone was enhanced beyond the optimal values. About $50 \%$ of shoots developed roots in a medium containing $0.4 \mathrm{mg} / \mathrm{lIAA}$; however, when the concentration of IAA was increased to $1 \mathrm{mg} / \mathrm{l}$, authors did not achieve any rooting. In their study, in vitro rooting was achieved in a medium fortified with either single hormone (NAA/2,4-D/IAA/IBA) in varying concentrations or in combinations (NAA + 2,4-D; 2,4-D + IAA; and 2,4-D + IBA). Among different media combinations, MS with the addition of NAA $(0.4 \mathrm{mg} / \mathrm{l})$, MS supplemented with 2,4-D $(0.4 \mathrm{mg} / \mathrm{l})$, and MS containing 2,4-D $(0.5-1 \mathrm{mg} / \mathrm{l})$ and NAA $(0.4 \mathrm{mg} / \mathrm{l})$ was reported to be the most effective media for in vitro rooting. Most micropropagation studies consider IBA or IAA to be the most effective plant PGRs for induction and proliferation of in vitro roots (Prodhan et al., 2016; Umamaheswari et al., 2014; Faheem et al., 2011). Furthermore, PGRs other than IBA or IAA have been reported to induce rooting in the in vitro regenerated shoots of $P$. kurroa. Lal and Ahuja (1996) reported that in vitro rooting in $P$. kurroa on an MS medium fortified with $2 \mathrm{mg} / \mathrm{l}$ NAA. Jan et al. (2009) successfully achieved in vitro rooting from micropropagated shoots of $P$. kurroa on NAA supplemented MS medium; however, the rooting response was enhanced when the medium was fortified with IBA or IAA. Patial et al. (2012) reported that the in vitro regenerated shoots of $P$. kurroa developed roots in a Knsupplemented medium as well as in a hormone-free medium. In most of the studies pertaining to the tissue culture of $P$. kurroa, only micropropagation data has been reported and very little information related to the acclimatization of micropropagated plants is available. A low-temperature requirement for the survival of the plant restricts the transplantation of the plants in natural conditions. Patial et al. (2016) in their study on P. kurroa emphasized the significance of the temperature for the survival of micropropagated plants during the process of acclimatization. They reported a $100 \%$ survival rate of the tissue culture-raised plants during transplantation to a glasshouse where the plants were incubated at $15^{\circ} \mathrm{C}$ for $\sim 10$ days before transplantation. Note that the survival rate decreased to $86 \%$ when the plants were transferred to a glasshouse without incubation at 
a low temperature prior to transplantation. In this study, plants with well-developed roots were excised and subjected to the acclimatization process and $\sim 62.4 \%$ plants survived and were successfully transplanted. Trivedi and Pandey (2007) utilized plant growth promoting rhizobacteria (PGPR) for improved biological hardening; however, in this study, successful acclimatization was achieved without using any PGPR.

\section{Conclusions}

We report an effective, easily reproducible protocol for the mass propagation and conservation of the endangered medicinal plant $P$. kurroa. The callus obtained may be cultured further via a suspension culture technique to evaluate the possibility of enhancing the production of bioactive compounds under the influence of different PGRs.

\section{Acknowledgement}

The authors are grateful to Dr. Hemant Sood Associate Professor, Department of Biotechnology and Bioinformatics, Jaypee University of Information Technology, Waknaghat, Solan, India for providing plants of Picrorhiza kurroa for this study.

\section{References}

Agarwal V.S. (2003) Directory of Indian Economic Plants. Bishen Singh Mahendra Pal Singh, Dehradun, India: 565.

Chaudhary V., Singh S., Vaid S., Sharma N. (2015) In vitro regeneration of Rauwolfia serpentina through anther culture studies. Biotechnol. Int. 8(3): 93-100.

Chaudhary V., Singh S., Sharma N. (2016) Direct in vitro regeneration from leaf segments of Rauwolfia serpentine. Int. J. Plant Animal Env. Sci. 6: 82-86.

Dogan M. (2017) Multiple shoot regeneration from shoot tip and nodal explants of Rotala rotundifolia (Buch-Ham. ex Roxb) Koehne. Anatol. J. Bot. 1(1): 4-8.

Faheem M., SinghS., Tanwer B S., Khan M., Shahzad A. (2011) In vitro regeneration of multiplication shoots in Catharanthus roseus - an important medicinal plant. Adv. Appl. Sci. Res. 2(1): 208-213.

Helena D.S., Kannojia G., Gaur A.K. (2015) In vitro regeneration of Picrorhiza kurroa Royal ex Benth for ex situ conser vation and sustainable utilization. Ann. Biol. Res. 6(5): 7-14.

Herath S.P., Suzuki T., Hattori K. (2004) Multiple shoot regeneration from young shoots of kenaf (Hibiscus cannabinus). Plant Cell Tissue Organ Cult. 77: 49-53.

Irshad S., Mannan A., Mirza B. (2011) Antimalarial activity of three Pakistani medicinal plants. Pak. J. Pharm. Sci. 24: 589-591.

Islam M.S., Bari M.A. (2013) Rapid in vitro multiplication, callogenesis and indirect shoot regeneration in Ipomoea mau- ritiana - a rare medicinal plant in Bangladesh. Med. Aromat. Plants. 2: 1-3.

Jan A., Phalisteen S.G., Thomas T., Shawl A. (2009) Auxin prompted improved micropropagation protocol of Picrorhiza kurroa: an endangered medicinal plant. Plant Tissue Cult. Biotech. 19(2): 161-167.

Kaviani B., Hesar A.A., Tarang A., Zanjani S.B., Hashemabadi D., Ansari M.H. (2013) Effect of kinetin (Kn) and naphthalene acetic acid (NAA) on the micropropagation of Matthiola incana using shoot tips, and callus induction and root formation on the leaf explants. Afr. J. Agricult. Res. 8: 4134-4139.

Lal N., Ahuja P.S. (1996) Plantlet regeneration from callus in Picrorhiza kurroa Royle ex Benth. - an endangered medicinal plant. Plant Tissue Cult. 6(2): 127-134.

Masood M., Arshad M., Qureshi R., Sabir S., Amjad M.S., Qureshi H., Tahir Z. (2015) Picrorhiza kurroa: an ethnopharmacologically important plant species of Himalayan region. Pure Appl. Biol. 4(3): 407-417.

Mathew M.K., Hariharan M. (1990) In vitro multiple shoot regeneration in Syzygium aromaticum. Ann. Bot. 65: 277-279.

Murashige T., Skoog F. (1962) A revised medium for rapid growth and bio-assays with tobacco tissue cultures. Physiol. Plants. 15: 473-497.

Niranjan M.H., Sudarshana M.S. Girisha S.T. (2010) In vitro multiple shoot induction from excised shoot tips and nodal segment explants of - Lagerstroemia indica (L.) - a medicinal cum Ornamental Shrub. J. Biomed. Sci. Res. 2(3): 212-217.

Ojha A., Kumar S., Singh R. (2012) Plant regeneration via somatic embryogenesis from root explants of Daucus carota L., subsp. Halophilus. Int. J. Phytomed. Rel. Ind. 4: 65-70.

Pandit S., Shitiz K., Sood H., Chauhan R.S. (2013) Differential biosynthesis and accumulation of picrosides in an endangered medicinal herb Picrorhiza kurroa. J. Plant Biochem. Biotech. 22(3): 335-342.

Parihar D., Bameta A., Kumari A., Kannojia G., Gaur A.K. (2018) Metabolite profiling of in vitro established cultures of Picrorhiza kurroa Royle ex Benth in different growth regime (s). Int. J. Pure App. Biosci. 6(2): 1663-1671.

Patial V., Devi K., Sharma M., Bhattacharya A., Singh A. (2012) Propagation of Picrorhiza kurroa Royle ex Benth: An important medicinal plant of Western Himalaya. J. Med. Plants Res. 6(34): 4848-4860.

Patial V., Sharma M., Bhattacharya A. (2016) Potential of thidiazuron in improved micropropagation of Picrorhiza kurroa - an endangered medicinal herb of alpine Himalaya. Plant Biosyst. Int. J. Dealing Aspects Plant Biol. 151: 729-736.

Prajapati N.D., Purohit S.S., Sharma A.K., Kumar T. (2007) $A$ handbook of medicinal plants. Jodhpur, Agrobios (India): 129.

Praveena C.S.V., Ramachandra R. (2013) Picroside and kutkoside enhancement studies on Picrorhiza kurroa by using Agrobacterium rhizogens mediated transformation. Int. J. Green Herbal. Chem. 2: 69-74. 
Prodhan S.H., Hasan N., Hoque H., Alam S.S., Hasan M.R., Gupta A., Khatun U.S., Parvin A., Joy Z.F. (2016) Development of an efficient in vitro regeneration system for endangered wild orange Citrus chrysocarpa L. Int. J. Sci. Basic Appl. Res. 30: 187-196.

Rajkumar V., Gunjan R., Ashok R. (2011) Antioxidant and antineoplastic activities of Picrorhiza kurroa extracts. Food Chem. Toxicol. 49: 363-369.

Salla H.R., Mohan C., Chandrashekara K.N. (2012) In vitro multiple shoot induction through axillary bud of Asclepias curassavica L. - a valuable medicinal plant. Int. J. Sci. Res. Publ. 2: 1-7.

Sharma N., Koshy E.P. (2017) Comparative analysis of in vitro regeneration potential of cotyledons of Withania somnifera and Withania coagulans. Plant Cell Biotech. Mol. Biol. 18(1-2): 22-29.

Sharma N., Koshy E.P., Sharma M.D. (2014) Indirect regeneration from leaf segments for mass propagation of Withania somnifera: an endangered medicinal plant. Int. J. Pharma. Biol. Sci. 5: 764-772.

Sharma N., Sharma M.D., Koshy E.P., Dhima M. (2015a) Micropropagation strategies for conservation of endangered medicinal plant Withania somnifera (L.) Dunal. J. Cell Tissue Res. 14(2): 4333-4338.

Sharma N., Sachdeva P., Dhiman M., Koshy E.P. (2015b) Comparative evaluation of in vitro regeneration potential of seeds of $W$. somnifera and $W$. coagulans. Biotech. Int. 8(1): 21-33.

Sharma N., Rautela R., Sharma M.D. (2016) Mass propagation and GC-MS analysis of critically endangered plant Withania coagulans. Int. J. Appl. Biol. Pharma Tech. 7: 62-70.

Sharma S., Katoch V., Rathour R., Sharma T.R. (2010) In vitro propagation of endangered temperate Himalayan medicinal herb Picrorhiza kurroa Royal ex Benth using leaf explants and nodal segments. J. Plant Biochem. Biotech. 19(1): 111-114.

Sharma S., Thokchom R. (2014) A review on endangered medicinal plants of India and their conservation. J. Crop Weed. 10(2): 205-218.

Singh H., Gahlan P., Dutt S., Ahuja P.S., Kumar S. (2011) Why uproot Picrorhiza kurroa. an endangered medicinal herb. Curr. Sci. 100: 1055-1059.
Sood H., Chauhan R.S. (2009) High frequency callus induction and plantlet regeneration from different explants of Picrorhiza kurroa - a medicinal herb of Himalayas. Afr. J. Biotech. 8(9): 1965-1972.

Srivastava G., Srivastava P. (2016) Biotechnological approach towards establishment of efficient production alternative for root derived phytomolecules with optimized yield enhancement parameter from Agrobacterium mediated "hairy root" cultures of Picrorhiza kurroa Royal ex Benth. J. Med. Plants Studies 4(6): 30-37.

Stuppner H., Wagner H. (1989) New cucurbitacin glycosides from Picrorhiza kurroa. Planta Med. 55: 559-563.

Tejavathi D.H., Devaraj V.R., Murthy S.M., Anitha P., Nijagunaiah R. (2010) Regeneration of multiple shoots from the callus cultures of Macrotyloma uniflorum (Lam.) Verdc. Indian J. Biotech. 9: 101-105.

Trivedi N., Dubey A. (2014) Efficient callus regeneration and multiple shoot induction in Brassica juncea var. Pusa Jaikisan. Res. J. Recent Sci. 3: 16-19.

Trivedi P., Pandey A. (2007) Biological hardening of micropropagated Picrorhiza kurroa Royal ex Benth., an endangered species of medical importance. World J. Microbiol. Biotechnol. 23: 877-878.

Umamaheswari C., Ambethkar A., Margaret F.S., Selvaraj N. (2014) In vitro multiple shoot regeneration from cotyledon explants of Luffa acutangula (L.) Roxb. Int. J. Curr. Biotechnol. 2(7): 7-13.

Venkatachalam P., Jayabalan N. (1997) Effect of auxins and cytokinins on efficient plant regeneration and multipleshoot formation from cotyledons and cotyledonary-node expiants of groundnut (Arachis hypogaea L.) by in vitro culture technology. Appl. Biochem. Biotech. 67: 237-247.

Vishwakarma U.R., Gurav A.M., Sharma P.C. (2013) Regeneration of multiple shoots from petiole callus of Viola serpens Wall. Pharmacognosy Res. 5: 86-92.

Weinges K., Kloss P., Henkels W.D. (1972) Natural products from medicinal plants. XVII. picroside-II, a new 6-vanilloylcatapol from Picrorhiza kurroa Royle and Benth. Justus Liebigs Ann. Chem. 759: 173-182. 